\title{
Improved Hydrophilicity of Membrane by Ethylenediaminetetraacetic Acid Modification
}

\author{
M. K. Chan* \& M. Letchumanan \\ Center of Water Research, Faculty of Engineering and the Built Environment, SEGi \\ University, 9 Jalan Teknologi, Taman Sains Selangor, PJU 5, Kota Damansara, 47810 \\ Petaling Jaya, Selangor, Malaysia
}

Submitted: 17/8/2018. Revised edition: 30/10/2018. Accepted: 1/11/2018. Available online: 5/12/2018

\begin{abstract}
Hydrophilic membranes exhibit good flux and low fouling tendency, which are the crucial criteria for a good membrane. Attempts have been done by researchers over the past decades to enhance the hydrophilicity of membrane by using nanoparticles and grafting. However, these processes are tedious and costly. This study improves the hydrophilicity of cellulose acetate (CA) membranes by using ethylenediaminetetraacetic acid (EDTA) via simple blending method. Recent study showed that fouled membrane which was cleaned by EDTA exhibited high water flux performance. However, the use of EDTA in formulating a membrane has not been disclosed elsewhere. Thus, the objective of this study is to conduct a series of experiments to find out the role of EDTA in improving the hydrophilicity of CA membranes. Membranes with varying EDTA concentration were prepared via dry-wet phase inversion technique. Contact angle, porosity and water flux of the resultant membranes were determined. Additionally, the morphologies of the membranes were imaged using FESEM. Results showed that EDTA was a good pore former, which can be seen clearly from FESEM images. This explains for the high porosity properties in CA-EDTA membranes. Membrane with $1 \mathrm{wt} \%$ of EDTA showed the highest water flux, which was $\sim 15 \mathrm{~L} /\left(\mathrm{h} . \mathrm{m}^{2}\right)$. Meanwhile, no water flux was observed after three hours when pure CA membrane was used in a dead-end filtration cell. In conclusion, EDTA is a promising additive in improving the hydrophilicity of membranes.
\end{abstract}

Keywords: EDTA, hydrophilicity, membrane, cellulose acetate

\subsection{INTRODUCTION}

Membrane, which separates the desired molecules from a mixture selectively, is widely used in food processing, pharmaceutical and wastewater industries due to its low energy consumption and excellent separation performance. In Netherlands, reverse osmosis membranes are used to produce demineralized water from secondary wastewater effluent, river water and surface water [1]. In cheese production industry, microfiltration membrane is used to remove bacteria from raw milk and enrich the casein content in cheese milk [2].
The efficiency of a membrane is governed by its surface property, for instance the hydrophilicity. A hydrophilic membrane is less prone to foul and exhibit high water flux during the separation process. Zhang et al. [3] found that the flux of membrane increased from 3950.8 to $5868.3 \mathrm{Lm}^{-2} \mathrm{~h}^{-}$ ${ }^{1} / \mathrm{MPa}$ when the contact angle reduced from $91^{\circ}$ to $65^{\circ}$ due to the addition of capsaicin-mimic material in polysulfone / polyethersulfone composite membrane. Additionally, no obvious flux decline found after conducting the biofouling test on the

\footnotetext{
* Corresponding to: M. K. Chan (email: mkchan@segi.edu.my)

https://doi.org/10.11113/amst.v23n1.135
} 
Table 1 Recent attempts to improve the hydrophilicity of cellulosic membranes

\begin{tabular}{|c|c|c|}
\hline Method & Performance & Reference \\
\hline $\begin{array}{l}\text { Regenerated cellulose membrane was } \\
\text { dip coated with silver nanoparticle. }\end{array}$ & $\begin{array}{l}\text { The growth of } E \text {. coli on the } \\
\text { membrane was inhibited due to } \\
\text { the presence of silver } \\
\text { nanoparticle. }\end{array}$ & [5] \\
\hline $\begin{array}{l}\text { Cellulose acetate membrane was firstly } \\
\text { immersed in silver nitrate solution and } \\
\text { it was reduced using hydroxylamine } \\
\text { reducing agent. }\end{array}$ & $\begin{array}{l}\text { The water permeability of the } \\
\text { modified membrane was } 1651 \\
\mathrm{~L} / \mathrm{h} \cdot \mathrm{m}^{2} \text {, which was } \\
\text { approximately } 7 \text { times higher } \\
\text { than the pure membrane. }\end{array}$ & [6] \\
\hline $\begin{array}{l}\text { Titanium dioxide nanofibers was } \\
\text { blended in cellulose acetate polymeric } \\
\text { solution before phase inversion process. }\end{array}$ & $\begin{array}{l}\text { The contact angle of membrane } \\
\text { reduced from } \sim 90^{\circ} \text { to } \sim 50^{\circ} \text { with } \\
\text { the addition of titanium dioxide } \\
\text { nanofibers. }\end{array}$ & [7] \\
\hline $\begin{array}{l}\text { Acetylated methyl cellulose (AMC) was } \\
\text { blended with cellulose acetate graft- } \\
\text { (glycidylmethacrylate-graft- } \\
\text { polyethylene glycol) before phase } \\
\text { inversion process. }\end{array}$ & $\begin{array}{l}\text { The water flux of blended } \\
\text { membrane was } 50 \% \text { higher } \\
\text { compared to pure AMC } \\
\text { membrane. }\end{array}$ & [8] \\
\hline
\end{tabular}

modified membrane, which indicated an excellent antifouling property. Similar finding was reported by Goetz et al. [4] where the water flux of cellulose acetate membrane was improved from 13400 to $14000 \mathrm{~L} / \mathrm{m}^{2} \mathrm{~h}$ when the contact angle reduced from $136.8^{\circ}$ to $0^{\circ}$ after chitin coating on the membrane surface. The coated membrane also exhibited good resistance to bovine serum albumin and humic acid, which are popular foulants.

Attempts have been done by researchers to improve the hydrophilicity of cellulosic membranes, as shown in Table 1. Benavente et al. [5], Pereira et al. [6] and Neelapala et al. [7] improved the hydrophilicity of membranes by using nanoparticles. The findings showed that the modified membranes exhibited excellent E-coli inhibition, high flux and low contact angle properties. However, the method to synthesize nanoparticles was tedious and costly. Jayalakshmi et al. [8] produced cellulose acetate graft(glycidylmethacrylate-graft-polyethylene glycol) and blended this polymer with acetylated methyl cellulose (AMC). 389.2 $\mathrm{L} /\left(\mathrm{m}^{2} \mathrm{~h}\right)$ of water flux for the blended membrane was reported and it was $50 \%$ higher compared to pure AMC membrane. This showed that grafting approach was effective, however the entire grafting process took at least 36 hours.

Ethylenediaminetetraacetic acid (EDTA) exhibits high affinity to heavy metal ions. It is widely used to clean the fouled membranes $[9,10]$. Tu et al. [11] found that the hydrophilicity of polyamide membrane increased after it was cleaned by EDTA. The contact angle of the cleaned membrane reduced and the water permeability increased. Recently, Zhang et al. [12] grafted diazo resin and EDTA layers on the surface of polyacrylonitrile (PAN) membrane. They found that water flux increased from 733 to $1068 \mathrm{~g} / \mathrm{m}^{2} \mathrm{~h}$, compared to the pure PAN membrane. Additionally, the modified membrane showed excellent ion copper adsorption. Thus, it is reasonable to conclude that EDTA played an important role in 
improving the hydrophilicity of membrane.

The focus of this study is to determine the effect of EDTA on cellulose acetate (CA) membrane, which has not been studied elsewhere. The CA/EDTA solution was prepared by simple blending microwave method. Microwave method was chosen due to shorter polymer dissolution time and lower energy consumption [13] compared to conventional thermal heating method. Once the bubble free solution was obtained, membrane was fabricated via dry phase inversion technique and the performance was evaluated in terms of pure water permeation. Contact angle goniometer and scanning electron microscope were used to characterise the membranes.

\subsection{METHODS}

\subsection{Materials}

Cellulose acetate with molecular weight of $100 \mathrm{kDa}$ was supplied by Acros, while dimethylformamide (DMF) and EDTA were supplied by Fisher Scientific. All the chemicals were used without further purification.

\subsection{Membrane Fabrication}

Polymeric solution with $20 \mathrm{wt} \%$ of CA in DMF were prepared in microwave at 300 watts for 2 minutes. The heated solution was stirred for additional 15 minutes before kept in a Schott bottle. The solution was kept for 48 hours to remove bubbles. A manual casting machine [14] was used to cast the CA solutions. The casting blade was adjusted to produce approximately $100 \mu \mathrm{m}$ membranes. The cast film was placed in oven at $50^{\circ} \mathrm{C}$ for 9 minutes before placed into RO water bath. The membrane fabricated from this solution was labelled as CA0. The same method was repeated by adding 1, 2, $3 \mathrm{wt} \%$ of EDTA into DMF. The fabricated membrane was labelled as CA1, CA2 and CA3 respectively.

\subsection{Membranes Characterization}

The thickness of a wet membrane was measured using digital micrometer (Mitutoyo) at 100 different spots on the membrane.

Contact angle of membrane was determined by sessile drop technique using Attension Theta Automatic gonioneter. $3 \mu 1$ of water droplet was placed on a membrane and at least 5 data was collected for every membrane.

Porosity of membrane was measured by gravimetric method and it was calculated by Equation 1:

$\varepsilon=\frac{\left(w_{a}-w_{b}\right) / \rho_{\text {water }}}{\left(w_{a}-w_{b}\right) / \rho_{\text {water }}+w_{b} / \rho_{\text {membrane }}}(1)$

where $w_{a}$ and $w_{b}$ are the wet and dry weights of the membranes respectively. $\rho_{\text {water }}$ is the density of water while $\rho_{\text {membrane }}$ is the density of membrane.

The membrane was broken using liquid nitrogen to obtain a clear cut section for imaging purpose. The sample was gold coated and imaged by using Field-Emission Scanning Electron Microscope (FESEM, Hitachi SU8010).

Milipore dead end stirred cell was used to measure the water flux. Membrane with effective surface area of $13.4 \mathrm{~cm}^{2}$ was used and the flux experiment was conducted at 1 bar for 3 hours.

\subsection{RESULTS AND DISCUSSION}

\subsection{Effect of EDTA on CA Membranes}

Figure 1 shows the advantageous effect of EDTA on water flux of membranes. 


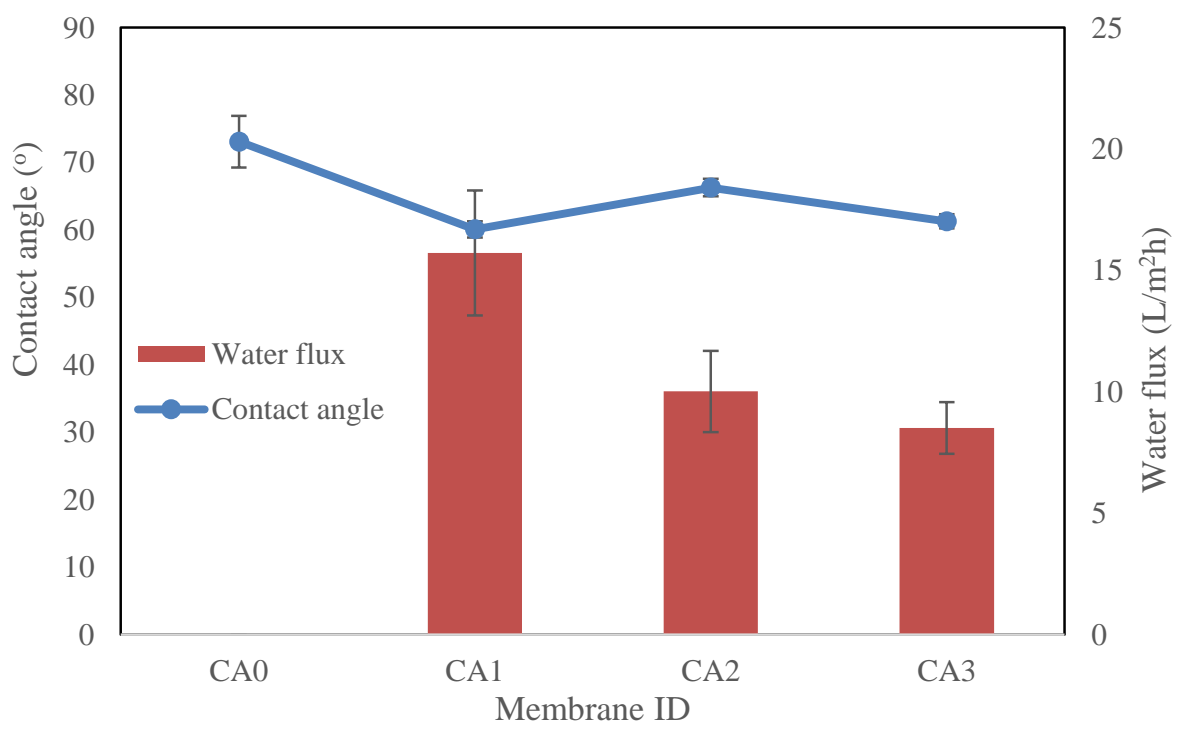

Figure 1 Effect EDTA on the contact angle and water flux of CA membranes

CA1 membrane produced $\sim 15 \mathrm{~L} / \mathrm{h} . \mathrm{m}^{2}$ of water flux. Comparatively, no water flux was observed after 3 hours of experiment using pure CA membrane, CA0. It proved that EDTA improved the hydrophilicity of CA membrane. This was further confirmed by the contact angle data, where CA0 was $\sim 73^{\circ}$, and it reduced to $\sim 60^{\circ}$ in CA1. Slightly reduce in water flux was found when more than $1 \mathrm{wt} \%$ of EDTA was used to fabricate CA membranes. It may due to the increase in the thickness of the respective membranes, as showed in Figure 2. The thickness of the membrane increased from $\sim 140$ to 160 $\mu \mathrm{m}$ when then the $\mathrm{wt} \%$ of EDTA increased from $1 \mathrm{wt} \%$ to $3 \mathrm{wt} \%$. Thicker membrane increases the membrane resistance and thus it required a longer time for water molecule to pass through the membrane $[15,16]$. Nevertheless, the contact angle of $\mathrm{CA} 2$ and $\mathrm{CA} 3$ were lower than CA 0 as showed in Figure 1. This proved that EDTA contributed great effect in improving the hydrophilicity of $\mathrm{CA}$ membranes.

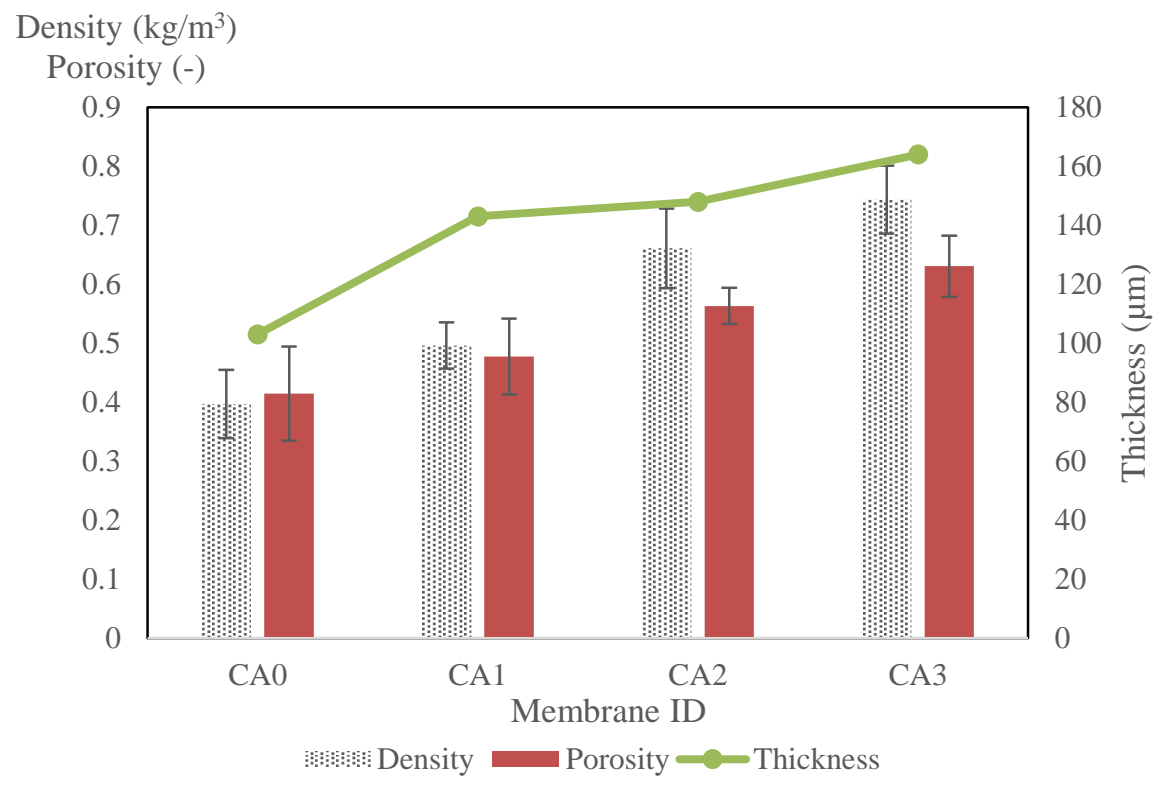

Figure 2 Density, porosity and thickness data of CA membranes 
It was notable that CA0 was the thinnest CA membrane, but no water flux was recorded. It was due to the high contact angle, which was $\sim 73^{\circ}$. This indicates that the surface of $\mathrm{CA} 0$ was more

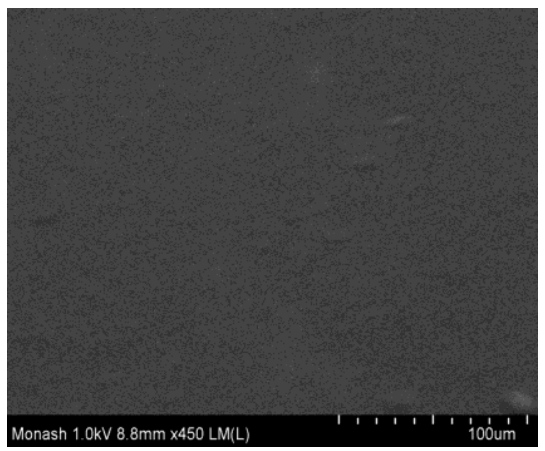

(a)

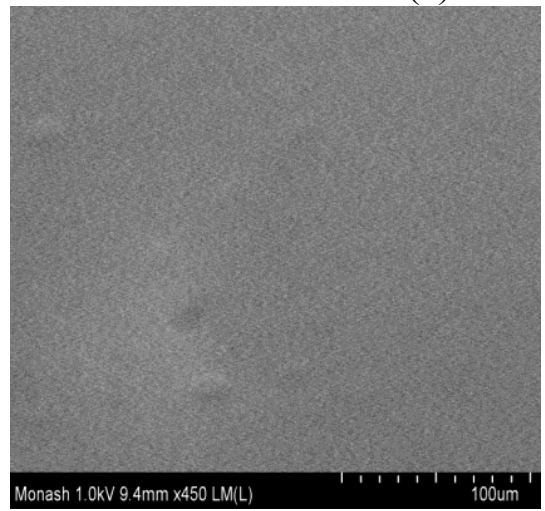

(c)

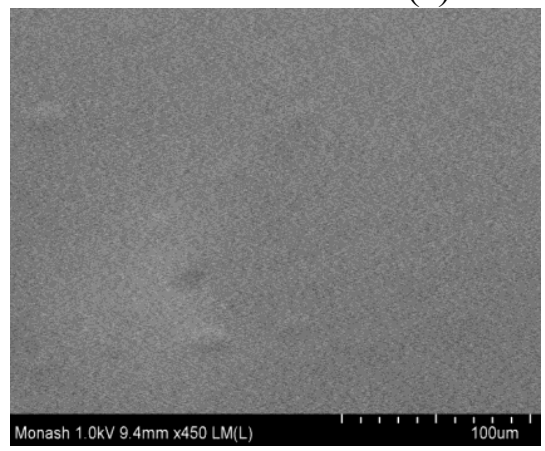

(e)

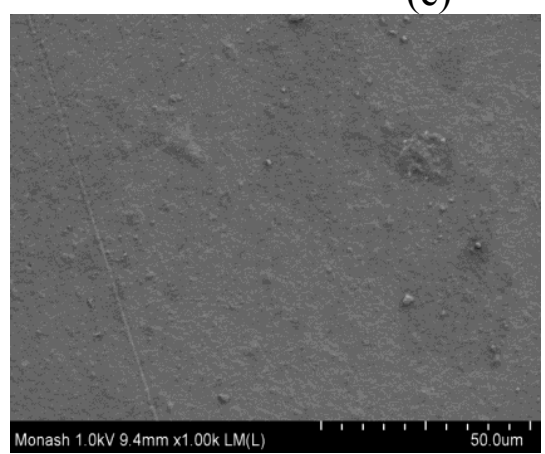

(g) hydrophobic compare to other CA membranes. Additionally, CA0 membrane exhibited the lowest porosity among the $\mathrm{CA}$ membranes as it

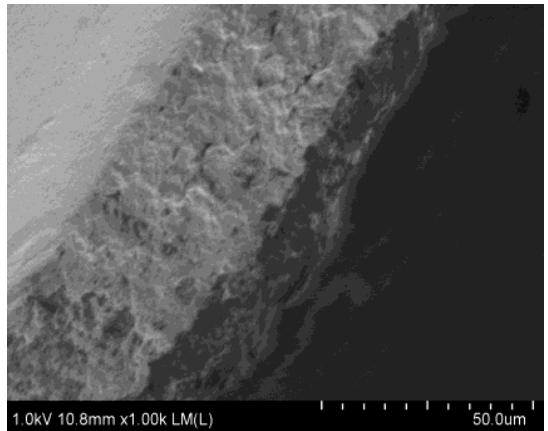

(b)

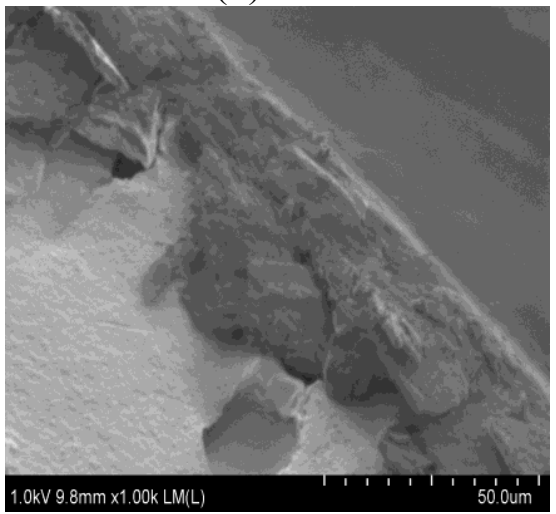

(d)

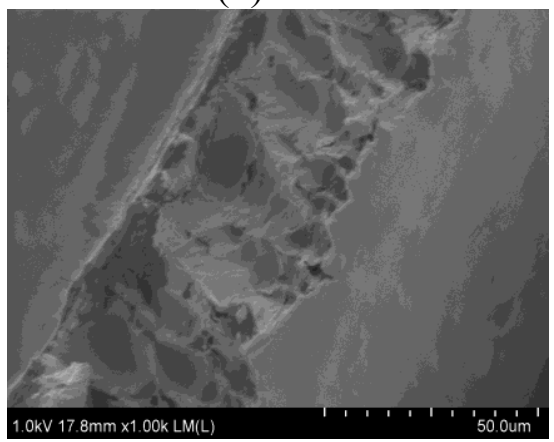

(f)

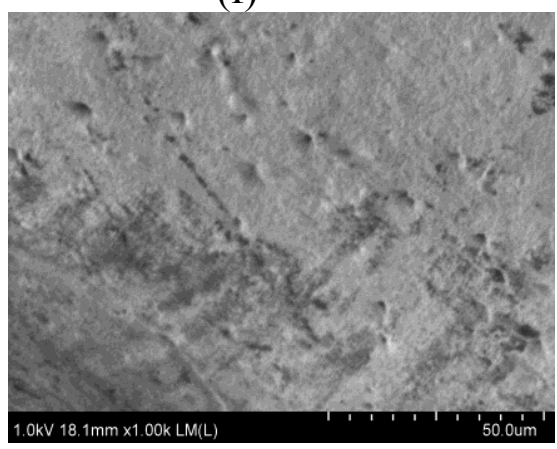

(h)

Figure 3 Surface and cross sectional images for (a-b) CA0, (c-d) CA1, (e-f) CA2 and (g-h) CA3 membranes 
exhibited the highest resistance to water flow.

Figure 2 shows that the density of membrane increased from CA 0 to CA3 membranes. This can be explained by the presence of EDTA in the membrane. EDTA, which is a pore former, as showed in FESEM image, Figure 3(d), increased the porosity of the membrane. High porosity implies high number of voids in the membrane. Indirectly, this shows that the membrane volume which was occupied by cellulose chains was low. Since density is equals to mass divided by volume, CA3 membrane, which has the highest porosity exhibited the highest density value.

Figure 3 shows the surface and cross sectional images of CA membranes. The FESEM images clearly showed that EDTA promoted instantaneous demixing and thus macrovoids were found in CA1 membrane. Compared to CA0, the membrane was dense and rough as shown in Figure 3(b). The size and number of voids increased as the EDTA content increased to $2 \mathrm{wt} \%$ in CA2, which as shown in Figure 3(f). However, further increase of EDTA content in the membrane suppressed the macrovoids and thus numerous fine pores was observed in Figure 3(h). This was due to the higher viscosity of CA3 solution compared to the other CA solutions. Viscous solution delayed the demixing process between CA3 solution and RO water, hence the macrovoids were suppressed.

Figure 3 shows the surface morphologies of all the CA membranes. CA membranes showed smooth surface, except for CA3 membranes, where a few nodules was found on the surface. This may due to the use of microwave heating during the $\mathrm{CA}$ solution preparation. According to Chan et al. [17], microwave active element like monosodium glutamate promoted chain scission phenomena, which reduced the skin integrity of CA membrane. EDTA is a microwave active element [18], thus similar phenomena was found in the CA solutions in this study. When concentration of EDTA was less than 3 $\mathrm{wt} \%$, the amount of heat generated was not sufficient to break the CA chains, thus smooth surfaces were observed in membranes CA1 and CA2. Chain scission occurred when preparing CA3 solution and hence a rough surface was found, as showed in Figure 3(g).

\subsection{CONCLUSION}

This study reveals the role of EDTA in improving the hydrophilicity of CA membranes. The contact angle of CA/EDTA was $5-10^{\circ}$ lower compared to pure CA membrane. Additionally, CA membrane with $1 \mathrm{wt} \%$ of EDTA showed the maximum water flux performance, which was approximately $15 \mathrm{~L} / \mathrm{m}^{2} \mathrm{~h}$. This membrane also shown high porosity and smooth surface, which are the important criteria for a good membrane. Therefore, EDTA is a promising additive in enhancing the membrane performance.

\section{ACKNOWLEDGEMENT}

Financial support from SEGi University (Research Fund: SEGiIRF/2015$01 /$ FoEBE-15/84) is gratefully acknowledged.

\section{REFERENCES}

[1] F. Beyer, J. Laurinonyte, A. Zwijnenburg, A. J. M. Stams, C. M. Plugge. 2017. Membrane Fouling and Chemical Cleaning in Three Full-scale Reverse Osmosis Plants Producing Demineralized Water. J. Eng. 2017: 6356751. 
[2] V. V. Mistry, J. L. Maubois. 2017. Chapter 27-Application of Membrane Separation Technology to Cheese Production. Cheese. Fourth Edition. Academic Press. 677-697.

[3] L. Zhang, C. Shan, X. Jiang, X. Li, L. Yu. 2018. High Hydrophilic Antifouling Membrane Modified with Capsaicin-mimic Moieties via Microwave Assistance (MWA) for Efficient Water Purification. Chem. Eng. J. 338: 688-699.

[4] L. A. Goetz, B. Jalvo, R. Rosal., A. P. Mathew. 2016. Superhydrophilic Anti-fouling Electrospun Cellulose Acetate Membranes Coated with Chitin Nanocrystals for Water Filtration. J. Membr. Sci. 510: 238-248.

[5] J. Benavente, M. E. Garcia, N. Urbano, J. M. Lopez-Romero, R. C. Contreras-Caceres, M. A. Casado-Rodriguez, A. Moscoso, J. Hierrezuelo. 2017. Inclusion of Silver Nanoparticles for Improving Regenerated Cellulose Membrane Performance and Reduction of Biofouling. Int. J. Biol. Macromol. 103: 758-763.

[6] B. S. Pereira, L. O. R. Moreti, M. F. Silva, R. Bergamasco, A. F. B. Piccioli, E. E. Garcia, W. V. Costa, E. A. G. Pineda, D. M. F. Oliveira, A. A. W. Hechenleitner. 2017. Permeability Increase in Ultrafiltration Cellulose Acetate Membrane Containing Silver Nanoparticles. Mat. Res. 20: 887891.

[7] S. D. Neelapala, A. K. Nair, P. E. JagadeeshBabu. 2017. Synthesis and Characteristic of $\mathrm{TiO}_{2}$ Nanofibre/Cellulose Acetate Nanocomposite Ultrafiltration Membrane. J. Exp. Nanosci. 12: 152-165.

[8] A. Jayalakshmi, I. C. Kim, Y. N. Kwon. 2015. Cellulose Acetate graft-(glycidlmethacrylate-gPEG) for modification of AMC Ultrafiltration Membranes to Mitigate Organic Fouling. RSC Adv. 5: 48290-48300.

[9] L. Masse, J. P. Bargues, M. Mondor, L. Deschenes, G. Talbot. 2015. Efficiency of EDTA, SDS, and $\mathrm{NaOH}$ Solutions to Clean $\mathrm{RO}$ Membranes Processing Swine Wastewater. Sep. Sci. Technol. 50: 2509-2517.

[10] F. Beyer, J. Laurinonyte, A. Zwijnenburg, A. J. M. Stams, C. M. Plugge. 2017. Membrane Fouling and Chemical Cleaning in Three Full-scale Reverse Osmosis Plants Producing Demineralized Water. Journal of Engineering. Article ID 6356751, 14 pages.

[11] K. L. Tu, A. R. Chivas, L. D. Nghiem. 2015. Chemical Cleaning Effects on Properties and Separation Efficiency of an RO Membrane. Membr. Water Treat. 6: 141-160.

[12] X. Zhang, S. Yang, B. Yu, Q. Tan, X. Zhang, H. Cong. 2018. Advanced Modified Polyacrylonitrile Membrane with Enhanced Adsorption Property for Heavy Metal Ions. Sci. Rep. 8: 1260.

[13] Dogan, H., Hilmioglu, N. D. 2009. Dissolution of Cellulose with NMMO by Microwave Heating. Carbohydr. Polym. 75: 90-94.

[14] M. K. Chan, H. H. Teo. 2013. Industrial Design, MY 12-014360101.

[15] C. Pertile, M. Zanini, C. Baldasso, M. Z. Andrade, I. C. Tessaro, 2018. Evaluation of Membrane Microfiltration Fouling in Landfill Leachate Treatment. Revista Materia. 23.

[16] A. Sagle, B. Freeman. 2004. Fundamentals of Membranes for Water Treatment. The Future of 
Desalination in Texas: Texas Water Development Board.

[17] M. K. Chan, A. Idris. 2012. Modification of Cellulose Acetate Membrane Using Monosodium Glutamate Additives Prepared by Microwave Heating. J. Ind. Eng. Chem. 18: 2115-2123.
[18] O. Kaygili, T. Ates, S. Keser, A. A. Al-Ghamdi, F. Yakuphanoglu. 2014. Controlling of Dielectric Properties of Hydroxyapatite by Ethylenediamine Tetraacetic acid (EDTA) for Bone Healing Applications. Spectrochim. Acta A. 129: 268-273. 